\title{
Synthesis of Carbon Xerogels and their Application in Adsorption Studies of Caffeine and Diclofenac as Emerging Contaminants
}

\author{
S. Álvarez ${ }^{1}$, R.S. Ribeiro ${ }^{2}$, H.T. Gomes ${ }^{2}$, J.L. Sotelo ${ }^{1}$, J. García ${ }^{1+}$
}

(1) - Grupo de Catálisis y Procesos de Separación (CyPS), Departamento de Ingeniería Química, Facultad de Ciencias Químicas, Universidad Complutense de Madrid, Avda. Complutense s/n, 28040 Madrid, Spain.

(2) - LCM - Laboratory of Catalysis and Materials - Associate Laboratory LSRE/LCM, Department of Chemical and Biological Technology, School of Technology and Management, Polytechnic Institute of Bragança, Campus de Santa Apolónia, 5300-857 Bragança, Portugal.

\section{Abstract}

This work involves the application of carbon xerogels in the removal of two emerging contaminants, caffeine and diclofenac, from aqueous solutions. Textural characterization of the carbon xerogels prepared by polycondensation of resorcinol with formaldehyde (with a molar ratio of 1:2) has been investigated using $\mathrm{N}_{2}$ adsorption-desorption at $-196{ }^{\circ} \mathrm{C}$. Chemical surface groups were analyzed by FTIR spectroscopy, elemental microanalysis and determination of isoelectric point. The equilibrium tests were carried out using different weights of adsorbent and the experimental data were best correlated by Sips isotherm equation. The kinetic experimental data were described using pseudo-first and pseudo-second order kinetic models, being well described by a pseudo-second order model. The maximum adsorption capacity was observed for adsorption of caffeine onto a xerogel treated with urea solution $\left(182.5 \mathrm{mg} \cdot \mathrm{g}^{-1}\right)$, due to the presence of Lewis bases on its surface, which increase the adsorption affinity for organic compounds. On the other hand, the higher extent of diclofenac adsorption was obtained with a carbon xerogel treated with sulphuric acid (80.0 mg. $\mathrm{g}^{-1}$ ), mainly due to electronic interactions. Comparing these results with other data reported in the literature, the carbon xerogels employed in our study were found to exhibit comparable adsorption capacities and higher kinetic properties.

Keywords: Adsorption; caffeine; carbon xerogel; diclofenac; emerging contaminant

${ }^{\dagger}$ Corresponding author: Tel.: +34-91-394-5207; Fax: +34-91-394-4114.E-mail address: jgarciar@ucm.es 


\section{Introduction}

An increasing number of emerging contaminants have been detected in surface waters of Europe, which is a topic of actual concern for international scientific and legislative communities. Generally, these compounds, e.g., pharmaceuticals, surfactants, pesticides, brominated flame retardants and personal care products are not totally removed by conventional wastewater treatment plants (WWTP), due to its ubiquitous and non-biodegradable character. Many of these substances are suspected to have endocrine-disrupting effects, possibly at long-term, in living organisms, including humans (Nikolaou et al. 2007).

In these categories, pharmaceuticals are a group of substances of high relevance, since it has been reported that 3000 different pharmaceutical compounds are on the market throughout European Union. Among these, several classes, such as antibiotics, anti-inflammatory and analgesic drugs, lipid regulators, beta-blockers, steroids and hormones, antiepileptic drugs, diuretics and cancer therapeutics have been detected in wastewater, groundwater and even drinking waters (Halling-Sǿrensen et al. 1998; Termes, 1998; Kümmerer et al. 2000; Kolpin et al. 2002).

Caffeine is one of the most widespread pharmaceuticals, usually proposed as tracer of human pollution, since it can be almost entirely human-related. The presence of caffeine has been detected in water from wells (Seiler et al. 1999), in Boston Harbor seawater (Siegener et al. 2002) and in Swiss lakes and rivers (Buerge et al. 2003), indicating that this compound can be used as indicator of domestic pollution. It is generally present in WWTP effluents and surface waters, having been detected in U.S. streams at maximum levels of $6.0 \mu \mathrm{g} . \mathrm{L}^{-1}$ (Kolpin et al. 2004).

Diclofenac is an anti-inflammatory drug, extensively used to treat inflammation and pain in pathologies as rheumatoid arthritis. Diclofenac is the compound having the highest acute toxicity within the Non-Steroidal Anti-inflammatory Drugs (NSAID), showing $\mathrm{EC}_{50}$ values lower than $100 \mathrm{mg} . \mathrm{L}^{-1}$ for all the tests performed (Cleuvers, 2003).

This drug has been frequently detected in wastewater at a median concentration of $0.81 \mu \mathrm{g} . \mathrm{L}^{-1}$, and the maximal values in wastewater and surface water is up to $2 \mu \mathrm{g} . \mathrm{L}^{-1}$. Due to its evidenced ecotoxicity and low removal percentages in WWTP, this compound has been recently included in the List of Priority Contaminants, regulated by 2013/39/EU Directive (Oaks et al. 2004; Triebskom et al. 2004).

Advanced Oxidation Processes are efficient technologies to degrade recalcitrant contaminants; however, intermediates of acute toxicity may be generated during the 
process. So, adsorption can be presented as an efficient alternative in the removal of micro-pollutants from wastewaters (Faria et al. 2008; Sotelo et al. 2013a; Sotelo et al. 2013b). Commercial adsorbents, usually showing microporous character, have been tested in the removal of these compounds, leading to extensive operation times. On the other hand, mesoporous carbons can adsorb larger molecules, such as dyes or organic compounds, providing better kinetic performance.

To the best of our knowledge, there are not many studies focused on the elimination of emerging contaminants by synthesized materials with extended mesoporosity. In this sense, the synthesis of carbon xerogels and their application as adsorbents of micropollutants have been carried out. In 1989, Pekala et al. (Pekala, 1989; Pekala et al. 1989) demonstrated that some chemical reactions by sol-gel transitions lead to nanoporous organic gels. The polymerization reaction of resorcinol (1,3-dihydroxybenzene) and formaldehyde generates the formation of organic gels with high porosity (> $80 \%$ ), large specific surface area (400-900 $\left.\mathrm{m}^{2} \cdot \mathrm{g}^{-1}\right)$ and low density $\left(0.03 \mathrm{~g} \cdot \mathrm{cm}^{-3}\right)$ (Pekala et al. 1993).

Previous works have shown that polymerization conditions, e.g. [resorcinol]/[formaldehyde] ratio, dilution ratio, $\mathrm{pH}$ of solution, and synthesis temperature affect the structure and properties of these organic xerogels. The high specific surface areas and conductivity obtained make these materials good candidates for the preparation of electrodes for fuel cells (Figueiredo et al. 2006); therefore, their well-developed pore texture is a great advantage in the fields of adsorption and catalysts supports. Their applications as adsorbents are recently increasing and present promising results for the removal of several dyes (Girgis et al. 2011; Figueiredo et al. 2011; Han et al. 2000; Ribeiro et al. 2012) and metals (Girgis et al. 2012).

From our knowledge, few relevant studies about adsorption of micro-pollutants onto carbon xerogels have been reported. Examples are the works of Carabineiro et al. (Carabineiro et al. 2011; Carabineiro et al. 2012) in which they studied the removal of the antibiotic ciprofloxacin. Therefore, in the present work, a carbon xerogel was prepared and subsequently subjected to several treatments in order to modify the nature and quantity of surface functional groups, leading to four carbon adsorbents with different textural and chemical properties. These materials were evaluated in the adsorption of two pharmaceuticals (caffeine and diclofenac), by performing kinetic studies and determining equilibrium adsorption isotherms, allowing to assess the effect of the surface chemistry on the adsorption of the selected micro-pollutants. 


\section{Materials and methods}

\subsection{Reactants.}

Caffeine and diclofenac were provided by Sigma-Aldrich (Steinheim, Germany), in analytical purity (> 99.99\%) and used in the experiments directly. The caffeine/diclofenac solutions were prepared by diluting stock solutions to the required concentrations.

Resorcinol (99 wt.\%) and formaldehyde solution (37 wt.\% in water, stabilized with 15 wt.\% methanol) were purchased from Sigma-Aldrich. Sulphuric acid (96-98 wt.\%), nitric acid (65 wt.\%) and urea (65 wt.\%) were obtained from Riedel-de-Haën. Sodium hydroxide (98 wt.\%) was obtained from Panreac.

\subsection{Synthesis procedure}

A carbon xerogel (CX) was prepared by polycondensation of resorcinol with formaldehyde (with a molar ratio of 1:2), following the procedure described elsewhere (Gomes et al. 2008): $9.91 \mathrm{~g}$ of resorcinol were added to $18.8 \mathrm{~mL}$ of deionised water in a glass flask. After complete dissolution, $13.5 \mathrm{~mL}$ of formaldehyde solution were also added. In order to achieve the desired initial $\mathrm{pH}$ of the precursor solution (6.1), sodium hydroxide solution was added drop wise under continuous stirring and $\mathrm{pH}$ monitoring. The gelation step was allowed to proceed at $85^{\circ} \mathrm{C}$ during 3 days.

After this period the gel was dark red and the consistency of the material allowed the sample to be grounded to obtain particle sizes in the range $0.106-0.250 \mathrm{~mm}$. The gel was then dried in oven during several days from $60{ }^{\circ} \mathrm{C}$ to $150{ }^{\circ} \mathrm{C}$, defining a heating ramp of $20{ }^{\circ} \mathrm{C}$. day $^{-1}$. After drying, the gel was calcined under a nitrogen flow $\left(100 \mathrm{~cm}^{3}\right.$ $\min ^{-1}$ ) at $120^{\circ} \mathrm{C}, 400{ }^{\circ} \mathrm{C}$ and $600{ }^{\circ} \mathrm{C}$ during $60 \mathrm{~min}$ at each temperature and then at 800 ${ }^{\circ} \mathrm{C}$ for $240 \mathrm{~min}$, defining a heating ramp of $2{ }^{\circ} \mathrm{C} \mathrm{min}^{-1}$, resulting in the $\mathrm{CX}$ material.

\subsection{Modification of the carbon xerogel}

The original CX material was modified by liquid phase, thermal and hydrothermal treatments, resulting in the production of three additional carbon xerogel samples, with different chemical properties and very similar textural features. These treatments were performed adapting the procedures reported elsewhere (Molina-Sabio et al. 1991; Gomes et al. 2010): a 50 g. $\mathrm{L}^{-1}$ mixture containing CX in concentrated sulphuric acid solution $\left(18\right.$ mol. $\left.\mathrm{L}^{-1}\right)$ was kept for $3 \mathrm{~h}$ at $200{ }^{\circ} \mathrm{C}$ in a $500 \mathrm{~mL}$ round-bottom flask heated by an oil bath; the recovered solids were thoroughly washed with distilled water until 
the neutrality of the rinsing waters was reached, and further dried in oven for $18 \mathrm{~h}$ at $110{ }^{\circ} \mathrm{C}$, resulting in the CXS material. A $50 \mathrm{~g} \mathrm{~L}^{-1}$ mixture containing $\mathrm{CX}$ in nitric acid (5 mol. $\mathrm{L}^{-1}$ ) was kept for $3 \mathrm{~h}$ at boiling temperature, the recovered solids being thoroughly washed with distilled water until the neutrality of the rinsing waters, and further dried in oven for $18 \mathrm{~h}$ at $110{ }^{\circ} \mathrm{C}$, resulting in the $\mathrm{CXN}$ material.

Finally, a $40 \mathrm{~g} \mathrm{~L}^{-1}$ mixture containing $\mathrm{CXN}$ in urea solution $\left(1 \mathrm{~mol} . \mathrm{L}^{-1}\right)$ was kept in a $125 \mathrm{~mL}$ stainless steel high pressure batch reactor under its own atmosphere at $200{ }^{\circ} \mathrm{C}$ for $2 \mathrm{~h}$; the recovered solids being thoroughly washed with distilled water until reach the neutrality, and further dried overnight in oven at $110{ }^{\circ} \mathrm{C}$; a gas phase thermal treatment was then applied under a nitrogen flow $\left(100 \mathrm{~cm}^{3} \cdot \mathrm{min}^{-1}\right)$, at $120{ }^{\circ} \mathrm{C}, 400{ }^{\circ} \mathrm{C}$ and $600{ }^{\circ} \mathrm{C}$ during $60 \mathrm{~min}$ at each temperature and then at $800{ }^{\circ} \mathrm{C}$ for $240 \mathrm{~min}$, resulting in the CXNUT material.

\subsection{Characterization of the carbon xerogels}

Textural characterization of the carbon xerogels were performed by $\mathrm{N}_{2}$ adsorption isotherms at $-196{ }^{\circ} \mathrm{C}$, using a Micromeritics ASAP 2010 apparatus. The specific surface area $\left(\mathrm{S}_{\mathrm{BET}}\right)$ was determined by the BET method; the volume of micropores $\left(\mathrm{V}_{0}\right)$ was calculated using the Dubinin-Radushkevich equation and the pore size distribution by the Barrett-Joyner-Halenda (BJH) method. The morphology of the materials was studied by scanning electron microscopy (SEM) with a JEOL JSM 6400 equipment at $22 \mathrm{keV}$.

IR spectra were recorded in the range $400-4600 \mathrm{~cm}^{-1}$ using a Thermo Nicolet FTIR spectrophotometer. Isoelectric point was measured using a Zeta sizer Nano ZS equipment using $0.05 \mathrm{~g}$ of sample suspended in $20 \mathrm{~mL}$ of deionized water. The $\mathrm{pH}$ was adjusted with either $0.1 \mathrm{M} \mathrm{HCl}$ or $0.1 \mathrm{M} \mathrm{NaOH}$ solutions.

\subsection{Kinetic and equilibrium adsorption experiments}

Adsorption kinetic tests were carried out using $25 \mathrm{~mL}$ Deltalab plastic vessels in a LabMate orbital shaker, by contacting $60 \mathrm{mg}$ of adsorbent $\left(\mathrm{d}_{\mathrm{p}}=0.106-0.250 \mathrm{~mm}\right)$ with $25 \mathrm{~mL}$ of solution. The temperature and shaking were controlled and maintained constants at $30 \pm 1{ }^{\circ} \mathrm{C}$ and $250 \mathrm{rpm}$, respectively. The vessels were removed at regular time intervals. The caffeine or diclofenac solution was filtered and analyzed in a Shimadzu UV-2401PC UV/Vis spectrophotometer. 
The adsorption equilibrium isotherms of the micro-pollutants were obtained by putting in contact $20 \mathrm{~mL}$ of caffeine or diclofenac solution, with an initial concentration of $100 \mathrm{mg} . \mathrm{L}^{-1}$, with different amounts of adsorbent in $25 \mathrm{~mL}$ plastic vessels. The vessels were located in an orbital shaker, at $30 \pm 1{ }^{\circ} \mathrm{C}$, until equilibrium was reached.

\section{Results and discussion}

\subsection{Characterization of the carbon xerogels}

Textural and chemical properties of the carbon xerogels are shown in Table 1. The $\mathrm{N}_{2}$ adsorption-desorption isotherms of the tested materials are shown in Figure 1. All the xerogels show a well-defined meso-macroporous structure, with an acceptable microporosity percentage. The presence of macropores is revealed by the sharp rising of the adsorption curve in the $\mathrm{N}_{2}$ adsorption-desorption isotherms at high relative pressures. The hysteresis cycles, especially in the case of the CXS material, are indicative of cylindrical mesoporous.

From Table 1 it can be observed that the materials present a high mesoporosity fraction $\left(\mathrm{V}_{\mathrm{m}} / \mathrm{V}_{\mathrm{P}}\right)$. The treatments lead to minimum changes in the micropore and mesopore volumes, while specific surface area suffered changes, mainly in the case of the CXS material. The reduction of the specific surface area from 367 to $288 \mathrm{~m}^{2} \cdot \mathrm{g}^{-1}$ in the production of the CXS material can be attributed to the severe oxidation conditions, which generates the formation of a more-developed macroporous structure.

\section{[Figure 1]}

Pore size distribution of carbon xerogels (Figure 2) was evaluated by the BarrettJoyner-Halenda method, confirming that all carbon xerogels are essentially mesoporous, with a medium pore diameter of $40 \mathrm{~nm}$, except for the CXS sample with a medium pore diameter of $25 \mathrm{~nm}$. Taking into consideration the application of the synthesized materials for adsorption of micropollutants in aqueous solution, it could be considered that the hydration of functional groups present on the surface of the materials, mainly due to the formation of hydrogen bonds, would reduce the pore diameter of the carbons. However, taking into account that the water molecule possesses a very small diameter of aproximately $0.275 \mathrm{~nm}$ (Graziano, 1998) - 100-fold inferior to the smaller average pore diameter of the carbon xerogels considered in this work - the influence of the hydration of functional groups on the medium pore diameter of the carbon xerogels may be considered negligible.

\section{[Figure 2]}


SEM micrographs were carried out in order to study the morphology of the materials (Figure 3). From the micrographs it can be observed that the particle size distribution is non-homogeneous, with particle diameters of several $\mu \mathrm{m}$. All carbons show smooth surfaces and that after the chemical and thermal treatments, no drastic morphological changes occurred, except for CXS. In this case, it seems that a more macroporous structure has been developed, maybe attributed to the formation of higher pores in the strong oxidation process with sulphuric acid, which could lead to the destruction of some pore walls. This is in agreement to the lower microporous character found in $\mathrm{N}_{2}$ adsorption-desorption isotherm of CXS.

\section{[Table 1]}

\section{[Figure 3]}

The FTIR spectra of the tested carbon xerogels are shown in Figure 4. In spite of the fact that the FTIR measurement procedure applied here makes it impossible to compare quantitatively the spectra obtained for the different carbon xerogels, the recorded bands clearly indicate which surface groups may be present (Biniak et al. 1997).

In all the spectra, a broad band can be found at $3600-3200 \mathrm{~cm}^{-1}$, specially intense for the $\mathrm{CX}$ material, due to the $\mathrm{O}-\mathrm{H}$ stretching vibrations, characteristic of the presence of surface hydroxylic groups and chemisorbed water. The assymetry of this band at lower wave numbers, occurring in all the carbon samples, is characteristic of strong hydrogen bonds (O'Reilly et al. 1983). The same band shape of $3400 \mathrm{~cm}^{-1}$ in the nitric acid and urea treated xerogels (CXN, CXNUT) supports that $\mathrm{N}-\mathrm{H}$ (amine groups) were not formed during the treatments.

The presence of absorption bands at 2956, 2921, 2851, 1468, 1340 and $460 \mathrm{~cm}^{-1}$ in all the FTIR spectra is characteristic of the presence of $\mathrm{C}-\mathrm{H}$ stretching vibrations in alkane or alkene groups on the surface of the carbons (Fanning et al. 1993; Suh et al. 1993; Vinke et al. 1994). There are bands at i) $1710 \mathrm{~cm}^{-1}$, ii) $1645 \mathrm{~cm}^{-1}$ and iii) 1560 $\mathrm{cm}^{-1}$ which can be attributed to the stretching vibrations of $\mathrm{C}=\mathrm{O}$ moieties in i) carboxylic, ester and lactones; ii) quinone and/or ion-radical structures; and iii) diketone, ketoester and keto-enol structures (Sellini et al. 1990; Fanning et al. 1993; Suh et al. 1993; Vinke et al. 1994). There is an overlapping in the range of 1470-1380 $\mathrm{cm}^{-1}$ that can be attributed to carboxyl-carbonate groups, vibrations of hydroxyl groups, $\mathrm{C}-\mathrm{H}$ vibrations and/or C-N- vibrations in heterocyclic structures (Meldrum et al. 1990; Sellitti et al. 1990; Fanning et al. 1993). 
The high intensity of the $2360 \mathrm{~cm}^{-1}$ absorption band on CXN and CXNUT materials could be related to the $\mathrm{C}-\mathrm{O}$ group, associated with uncompensated atmospheric $\mathrm{CO}_{2}$. Absorption bands below $900 \mathrm{~cm}^{-1}$ can be attributed to out-of-plane deformation vibrations of $\mathrm{C}-\mathrm{H}$ groups located at the edges of the aromatic planes (Meldrum et al. 1990).

After the treatments of the non-modified carbon xerogel (CX) with nitric acid, sulphuric acid and urea solution, the intensity of the carbonyl functional group band increases in i) carboxyl $\left(1710 \mathrm{~cm}^{-1}\right)$, ii) diketone, ketoester and keto-enol structures $\left(1572 \mathrm{~cm}^{-1}\right)$ as well as iii) the bands at $1350-1150 \mathrm{~cm}^{-1}$ range, especially for CXNUT, characteristic of the C-O vibrations (e.g. ester, ether, lactone, carboxyl or phenols) (Meldrum et al. 1990; Fanning et al. 1993; Suh et al. 1993).

\section{[Figure 4]}

From the elemental microanalysis and the $\mathrm{pH}_{\mathrm{IEP}}$ results shown in Table 1 it is observed that the treatment of CX with nitric acid results in the incorporation of acidic oxygen-containing functional groups (typically carboxylic acids), leading to a material $(\mathrm{CXN})$ with a high content of $\mathrm{O}$ and a very low $\mathrm{pH}_{\mathrm{IEP}}$ of 1.1. Further treatment of CXN with urea followed by heat-treatment under $\mathrm{N}_{2}$ atmosphere lead to the introduction of $\mathrm{N}$ and to a reduction of the $\mathrm{O}$ content, resulting in this case in a material (CXNUT) with a near neutral surface $\left(\mathrm{pH}_{\mathrm{IEP}}=6.9\right)$. An acidic material is also obtained when $\mathrm{CX}$ is treated with sulphuric acid $\left(\mathrm{CXS}, \mathrm{pH}_{\mathrm{IEP}}=2.8\right)$, this case is due to the incorporation of sulphur-containing functional groups, leading to the increase of $\mathrm{S}$ and $\mathrm{O}$ contents.

\subsection{Adsorption kinetic studies}

The kinetics of caffeine and diclofenac adsorption on the four carbon xerogels was evaluated (Figure $5 \mathrm{a}-\mathrm{b}$ ). The concentration of caffeine decreased drastically in the first $1 \mathrm{~h}$, for CX and CXNUT materials, developing later a gradual decreasing until total removal was reached after $48 \mathrm{~h}$. The removal percentage of caffeine onto CXS, $75.2 \%$, was the lowest in the adsorption tests.

A different behavior was observed for diclofenac, with this compound the highest removal was obtained with CXS. The decrease of diclofenac concentration in aqueous phase with the CX material was more gradual than in the case of caffeine, reaching a lower percentage removal.

For both cases, the higher removal rate of the compounds could be attributed to their larger affinity towards the chemical surface of the adsorbent, as it is explained 
below in Section 3.3. Equilibrium adsorption isotherm studies. Therefore, the tendency of the kinetic curves is in agreement to the adsorption isotherms behaviour observed in Figures 6 a-b.

Comparing the results obtained in this work (mesoporous carbon xerogel materials) with microporous materials, such as the F-400 activated carbon tested in a previous work (Sotelo et al. 2012), it is concluded that the microporous materials need a much longer period of time to reach equilibrium; in this case, the pore size distribution of the carbon xerogels, centered at $40 \mathrm{~nm}$, except in the CXS sample with a pore diameter of $25 \mathrm{~nm}$, is beneficial for the adsorption process, since the transport within the pores is not limited by steric hindrance.

\section{[Figure 5a-b]}

The experimental data were fitted to pseudo-first and pseudo-second order kinetic models, using the linearized expressions shown in Eq. (1) and (2), respectively.

$$
\begin{aligned}
& \ln \left(q_{e}-q\right)=\ln q_{e}-k_{1} \cdot t \\
& \frac{t}{q}=\frac{1}{k_{2} \cdot q_{e}^{2}}+\frac{t}{q_{e}}
\end{aligned}
$$

where, $\mathrm{q}_{\mathrm{e}}, \mathrm{mg} \mathrm{g}^{-1}$, and $\mathrm{q}, \mathrm{mg} \mathrm{g}^{-1}$, are equilibrium adsorption capacity and adsorption capacity at time $\mathrm{t}$, respectively, $\mathrm{k}_{1}, \mathrm{~h}^{-1}$, is the pseudo-first-order model rate constant, $\mathrm{k}_{2}$, g.mg ${ }^{-1} \cdot \mathrm{h}^{-1}$, the pseudo-second-order adsorption rate constant. The experimental, $\mathrm{q}_{\mathrm{e}} \mathrm{exp}$, and estimated, $\mathrm{q}_{\mathrm{e}} \mathrm{cal}$, equilibrium adsorption capacities and rate adsorption constants are summarized in Table 2.

It could be evidenced that the pseudo-second order model provides more accuracy between the experimental and predicted data, as can be checked from theoretical adsorption capacity and correlation coefficient values. In both cases, the pseudo-second order adsorption rate constants (Table 2) are in agreement with the experimental trend, i.e., higher kinetics for CXNUT in the case of caffeine and CXS material for diclofenac were obtained. The half adsorption time values, $t_{1 / 2}(h)$, defined as the time required to reaching $50 \%$ of saturation of the adsorbent capacity, are also in accordance to the $\mathrm{k}_{2}$ parameters for both contaminants.

\subsection{Equilibrium adsorption isotherm studies}

The isotherms of caffeine and diclofenac adsorption onto the synthesized carbon xerogels were investigated and are shown in Figures 6 a-b. 
The isotherms of caffeine onto CX and CXNUT materials and of diclofenac onto CX, CXNUT and CXS are of the S type (Giles et al. 1960), indicating that the energy of adsorption is dependent of the solution concentration and that the solvent contributes negatively, i.e., that water molecules compete with caffeine and diclofenac for the available active sites and/or that steric hindrance may occur in hydrated adsorbate molecules due to the blockage of the functional groups responsible for the establishment of the electronic interactions with the active sites. This behavior is especially evident for the CXNUT adsorbent. This could be explained by the caffeine and diclofenac molecules radius values, which are of $0.376 \mathrm{~nm}$ and $0.414 \mathrm{~nm}$, respectively (Jahagirdar et al. 2000; Urase et al. 2007). Despite the water molecule (diameter of $0.275 \mathrm{~nm}$, as previously reported) being smaller than these two molecules, steric hindrance may be observed. Furthermore, as the concentration in the aqueous phase increases, the adsorption occurs more readily. This is due to a synergistic effect with the adsorbed molecules facilitating the adsorption within the available sites of other molecules, as a result of adsorbate-adsorbate interactions, or cooperative adsorption (Gomez et al. 2007).

\section{[Table 2]}

\section{[Figure 6 a-b]}

In contrast to this situation, the adsorption isotherms of caffeine onto $\mathrm{CXN}$ and CXS are of high affinity type (Langmuir isotherm type), showing a steep initial slope since the water molecules offer no competition. The adsorption curve of diclofenac onto $\mathrm{CXN}$ is in the intermediate between $\mathrm{S}$ and Langmuir type, showing a small plateau, notcompletely saturated, after which a sudden rise occurs at a concentration of about 20 mg. $\mathrm{L}^{-1}$. As previously shown, this rise is due to a reorientation of the adsorbed molecules in a direction of a more dense packing, giving rise to more available space for adsorption (Helmy et al. 1983; Khattri and Singh, 2009).

Langmuir (Eq. 3), Freundlich (Eq. 4) and Sips (Eq. 5) adsorption models were used to fit the experimental equilibrium adsorption data:

$$
\begin{aligned}
& q_{e}=\frac{q_{s a t} \cdot b \cdot C_{e}}{1+b \cdot C_{e}} \\
& q_{e}=K_{F} \cdot C_{e}^{1 / n_{F}} \\
& q_{e}=\frac{q_{s a t} \cdot\left(b \cdot C_{e}\right)^{1 / n}}{1+\left(b \cdot C_{e}\right)^{1 / n}}
\end{aligned}
$$


where $\mathrm{C}_{\mathrm{e}}\left(\mathrm{mg} . \mathrm{L}^{-1}\right)$ represents the equilibrium concentration in the aqueous phase, $\mathrm{q}_{\mathrm{e}}$ $\left(\mathrm{mg} \cdot \mathrm{g}^{-1}\right)$, the equilibrium adsorption capacity, $\mathrm{q}_{\mathrm{sat}}\left(\mathrm{mg} \cdot \mathrm{g}^{-1}\right)$, the maximum adsorption capacity according to Langmuir and Sips models, b $\left(\mathrm{L}_{\mathrm{mg}}{ }^{-1}\right)$, a parameter related to the adsorption intensity for Langmuir and Sips equations, n, a constant associated with the heterogeneity of the adsorbent in Sips model, while $\mathrm{K}_{\mathrm{F}}\left(\mathrm{L} \cdot \mathrm{g}^{-1}\right)$ and $\mathrm{n}_{\mathrm{F}}$ are parameters which defines the adsorption capacity and adsorption intensity in the Freundlich model.

The adsorption model parameters can be seen in Table 3. The fitting error in the theoretical models was evaluated by the standard deviation parameter (SE):

$$
S E=\sqrt{\sum \frac{\left(q_{0(\mathrm{exp})}-q_{0(\mathrm{cal})}\right)^{2}}{N}}
$$

where $\mathrm{q}_{0(\exp )}$ is the experimental adsorption capacity, $\mathrm{q}_{0 \text { (cal) }}$, the theoretical adsorption capacity and $\mathrm{N}$ is the number of experimental points.

From Table 3 it can be concluded that the adsorption of caffeine onto CXN and CXS materials were best fitted by Langmuir equation, while adsorption of diclofenac onto CXN carbon were more accurately fitted by Freundlich equation. Also, the $\mathrm{n}_{\mathrm{F}}$ parameter of Freundlich equation is higher than 1 in all cases, indicating that the adsorption of caffeine and diclofenac is a favorable process (Chowdhury et al. 2011). From Table 3 it can be deduced that the Langmuir model fits more adequately the adsorption isotherms with a saturated plateau, and that Freundlich equation reproduces satisfactorily the curves in which the plateau is non-totally saturated.

In general terms, the Sips model provided the best fitting for all the experiments, since SE values were lower than the values obtained by the other two models. This behavior can be attributed to the higher complexity that Sips equation involves, having into account the heterogeneity of the solid surface.

\section{[Table 3]}

Table 4 shows a comparison between the maximum experimental adsorption capacities that were found in our studies and the adsorption removal of other contaminants by different carbon xerogels previously reported in the literature.

\section{[Table 4]}

A direct comparison is inapplicable due to the different characteristics of the contaminants, adsorbents and experimental conditions. However, it can be concluded 
that the carbon xerogels employed in our study provide significant adsorption capacity values, especially for caffeine, at the tested conditions.

In Figure 7 is depicted a comparison between the maximum adsorption capacity values of caffeine and diclofenac onto the carbon xerogels tested. For caffeine, the order in adsorption removal is CXNUT $>\mathrm{CX}>\mathrm{CXN} \sim \mathrm{CXS}$, while for diclofenac is CXS CXNUT $>$ CX $>$ CXN.

In general terms, caffeine is adsorbed in a higher extent than diclofenac, except for CXS material. In fact, caffeine is a more hydrophilic molecule than diclofenac; so, due to the mainly hydrophilic nature of the adsorbents (evidenced by the isoelectric point values shown in Table 1), there is a tendency for the adsorbent to adsorb preferably hydrophilic molecules, i.e. water molecules than pollutants. This is in agreement to the $\mathrm{S}$ type adsorption isotherms of diclofenac removal.

The maximum value of adsorption capacity, $182.5 \mathrm{mg} . \mathrm{g}^{-1}$, was obtained for caffeine adsorption onto the xerogel treated with urea solution. Furthermore, the adsorption isotherm (Figure 6a) evidenced a high affinity between caffeine and CXNUT, as evidenced by the sharp initial curve of the adsorption isotherm (at caffeine aqueous phase concentrations lower than $\left.10 \mathrm{mg} \cdot \mathrm{L}^{-1}\right)$.

\section{[Figure 7]}

Higher caffeine adsorption capacity values can be attributed to the porous structure of the adsorbent, since the CXNUT material presents the highest specific surface area among the tested solids. Another reason to explain the greater extent of the adsorption onto CXNUT material is the high number of mesopore channels, establishing a connection between mesopores and the microporous structure, highly contributing to achieve larger adsorption capacities (Kosuge et al. 2007). Referring to the basic/acid properties of the CXNUT material, it is well recognized that the urea solution treatment of carbon materials leads to the formation of pyridinic-N, cyano and amino groups, of basic character (Sousa et al. 2010). This is in agreement with the increase of the $\mathrm{N}$ content determined by elemental microanalysis (Table 1) compared to the CXN material, from 0.91 to $2.81 \mathrm{wt} \%$. These groups are generally Lewis bases that increase the available active sites for the removal of organic compounds, potentiating the adsorption affinity between the solutes and the urea treated carbon xerogel (Boehm, 2009). In addition, the more basic character of CXNUT xerogel $\left(\mathrm{pH}_{\mathrm{IEP}}=6.9\right)$ seems to enhance the caffeine removal. 
Related to the adsorption mechanism onto the CXS material, the adsorption capacity seems to be highly influenced by the adsorption energy. The octanol-water partition coefficient value, $\log \mathrm{K}_{\mathrm{ow}}$, reveals that diclofenac is more hydrophobic than caffeine. It has been extensively investigated that adsorption of organic compounds involving phenolic groups induce the formation of $\pi-\pi^{*}$ bonds. The groups present on the carbon surface treated with sulfuric acid (thiols, sulphides...) behave as $\pi$-electron donors (Terzyk, 2003) whereas the benzene rings in diclofenac structure present an electron-withdrawing character (Monneyron and Faur-Brasqet, 2002). Furthermore, the chloride substituents and the $-\mathrm{COOH}$ group decrease the electron density of the molecule, enhancing the adsorption affinity towards active sites of CXS carbon xerogel. This can explain the higher adsorption extent of diclofenac onto sulfuric acid treated carbon.

Furthermore, the initial adsorption rates (defined as h) of caffeine and diclofenac against the $\mathrm{pH}_{\mathrm{IEP}}$ values are plotted in Figure 8. It can be observed that CXNUT follows the apparent correlation between the surface chemistry and the initial adsorption rate of caffeine. As it can be seen, CXNUT shows a much faster initial rate compared to the other systems. The same is occurring for initial diclofenac adsorption rate on the CXS material. Summarizing, it can be concluded that the better performance of caffeine and diclofenac adsorption onto CXNUT and CXS carbon xerogels is directly related to the surface chemistry of the carbon xerogels and not strictly to their surface area. For instance, the caffeine specific removal on CXNUT amounts to $0.42 \mathrm{mg} \mathrm{m}^{-2}$, whereas only a removal of $0.37 \mathrm{mg} \mathrm{m}^{-2}$ is reached when the original CX is employed. CXS and CXN exhibit even lower specific removal capacities, $0.16 \mathrm{mg} \mathrm{m}^{-2}$ and $0.14 \mathrm{mg} \mathrm{m}^{-2}$ respectively.

\section{[Figure 8]}

\section{Conclusions}

In this work it is concluded that the chemical surface properties of carbon xerogel adsorbents play a major role in the adsorption of caffeine and diclofenac from aqueous solutions. In particular, a remarkable efficiency of CXNUT and CXS carbon xerogels has been evidenced for the removal of caffeine and diclofenac, respectively. In the case of the CXNUT material, the better performance can be directly associated to the increased presence of Lewis bases on the surface of the carbon, improving the adsorption of caffeine. On the other hand, the higher adsorption capacity of diclofenac, which shows electron-withdrawing character due to the presence of the benzene rings 
on its structure, can be related to the increase of $\pi$-electron donors on the surface of CXS.

The carbon xerogel oxidized with nitric acid, CXN, presents the worst performance, mainly due to the presence of large amounts of surface oxygenated groups of acidic nature $\left(\mathrm{pH}_{\mathrm{IEP}}=1.1\right)$, which attract $\pi$ electrons, decreasing the dispersive interactions with the adsorbate molecules.

When compared to some commercial activated carbons, carbon xerogels are interesting alternatives for the adsorption removal of caffeine/diclofenac, since better kinetic performance can be obtained. For instance, the equilibrium time can be reduced from $450 \mathrm{~h}$ (for the activated carbon F-400) to $48 \mathrm{~h}$ (for the carbon xerogels tested in this work) when adsorption of diclofenac is considered.

\section{Acknowledgements}

This work has been funded by Ministerio de Economía y Competitividad CTQ2011-27169 and Comunidad de Madrid through REMTAVARES Network S2009/AMB-1588 and partially supported by projects PTDC/AAC-AMB/110088/2009 and PEst-C/EQB/LA0020/2013, co-financed by FEDER through COMPETE, QREN and ON2, and by FCT - Fundação para a Ciência e a Tecnologia.

\section{References}

Boehm, H.P., 2009. Catalytic properties of nitrogen-containing carbons. In: Carbon Materials for Catalysis. Eds. P. Serp, J.L. Figueiredo (Eds.), Wiley, Hoboken, New Jersey 219-265.

Biniak, S., Szymanski, G., Siedlewski, J., Swiatkowski, A., 1997. The characterization of activated carbons with oxygen and nitrogen surface groups. Carbon $35,1799-1810$.

Buerge, I.J., Poiger, T., Müller, M.D., Buser, H.R., 2003. Caffeine, an anthropogenic marker for wastewater contamination of surface waters. Environ Sci Technol. 37, 691700.

Carabineiro, S.A.C., Thavorn-amornsri, T., Pereira, M.F.R., Figueiredo, J.L., 2011. Adsorption of ciprofloxacin on surface-modified carbon materials. Water Res. 45, 45834591. 
Carabineiro, S.A.C., Thavorn-amornsri, T., Pereira, M.F.R., Serp, P., Figueiredo, J.L., 2012. Comparison between activated carbon, carbon xerogel and carbon nanotubes for the adsorption of the antibiotic ciprofloxacin. Catal. Today 186, 29-34.

Chowdhury, S., Mishra, R., Saha, P., Kushwaha, P., 2011. Adsorption thermodynamics, kinetics and isosteric heat of adsorption of malachite green onto chemically modified rice husk. Desalination 265, 159-168.

Cleuvers, M., 2003. Aquatic ecotoxicity of pharmaceuticals including the assessment of combination effects. Toxicol. Lett. 142, 185-194.

Fanning, P.E., Vannice, M.A., 1993 A DRIFTS study of the formation of surface groups on carbon by oxidation. Carbon 31, 721-730.

Faria, P.C.C., Órfao, J.J.M., Figueiredo, J.L., Pereira, M.F.R., 2008. Adsorption of aromatic compounds from the biodegradation of azo dyes on activated carbon. Appl. Surf. Sci. 254, 3497-3503.

Figueiredo, J.L., Pereira, M.F.R., Serp, P., Kalck, P., Samant, P.V., Fernandes, J.B., 2006. Development of carbon nanotube and carbon xerogel supported catalysts for the electro-oxidation of methanol in fuel cells. Carbon 44, 2516-2522.

Figueiredo, J.L., Sousa, J.P.S., Orge, C.A., Pereira, M.F.R., Órfao, J.J.M., 2011. Adsorption of dyes on carbon xerogels and templated carbons: influence of surface chemistry. Adsorption 17, 431-441.

Giles, C.H., MacEwan, T.H., Nakhwa, S.N., Smith, D., 1960. Studies in adsorption. Part XI: A system of classification of solution adsorption isotherms, and its use in diagnosis of adsorption mechanism and in measurement of specific surface areas of solids. J. Chem. Soc. 3973-3993.

Girgis, B.S., El-Sherif, I.Y., Attia, A.A., Fathy, N.A., 2012. Textural and adsorption characteristics of carbon xerogel adsorbents for removal of $\mathrm{Cu}$ (II) ions from aqueous solution. J. Non-Cryst. Solids 358,741-747.

Girgis, B.S., Attia, A.A., Fathy, N.A., 2011. Potential of nano-carbon xerogels in the remediation of dye-contaminated water discharges. Desalination 265, 169-176.

Gomes, H.T., Machado, B.F., Ribeiro, A., Moreira, I., Rosário, M., Silva, A.M.T., Figueiredo, J.L., Faria, J.L., 2008. Catalytic properties of carbon materials for wet oxidation of aniline. J. Hazard. Mater. 159, 420-426.

Gomes, H.T., Miranda, S.M., Sampaio, M.J., Silva, A.M.T., Faria, J.L., 2010 Activated carbons treated with sulfuric acid: catalysts for catalytic wet peroxide oxidation. Catal. Today 151, 153-158. 
Gómez, V., Larrechi, M.S., Callao, M.P., 2007. Kinetic and adsorption study of acid dye removal using activated carbon. Chemosphere 69, 1151-1158.

Graziano, G., 1998. On the size dependence of hydrophobic hydration. J. Chem. Soc. Faraday T. 95, 3345-3352.

Halling-Sǿrensen, B., Nielsen, S.N., Lanzky, P.F., Ingerster, F., Lützhǿff, H.C.H., Jǿrgensen, S.E., 1998. Occurrence, fate and effects of pharmaceutical substances in the environment-a review. Chemosphere 36, 357-393.

Han, S., Sohn, K., Hyeon, T., 2000. Fabrication of new nanoporous carbons through silica templates and their application to the adsorption of bulky dyes. Chem. Mater. 12, 3337-3341.

Helmy, A.K., De Bussetti, S.G., Ferreiro, E.A., 1983. Adsorption of quinoline from aqueous solutions by some clays and oxides. Clay Clay Miner. 31, 29-36.

Jahagirdar, D.V., Arbad, B.R., Walkevar, A.A., Shankarwar, A.G. 2000. Studies in partial molar volumes, partial molar compressibilities and viscosity b-coefficients of caffeine in water at four temperatures. J. Mol. Liq. 85, 361-373.

Khattri, S.D., Singh, M.K., 2009. Removal of malachite green from dye wastewater using neem sawdust by adsorption. J. Hazard. Mater. 167, 1089-1094.

Kolpin, D.W., Furlong, E.T., Meyer, M.T., Thurman, E.M., Zaugg, S.D., Barber, L.B., Buxton, H.T., 2002. Pharmaceuticals, hormones, and other organic wastewater contaminants in US streams, 1999-2000: a national reconnaissance. Environ. Sci. Technol. 36, 1202-1211.

Kolpin, D.W., Skopec, M., Meyer, M.T., Furlong, E.T., Zaugg, S.D., 2004. Urban contribution of pharmaceuticals and other organic wastewater contaminants to streams during differing flow conditions. Sci. Total Environ. 328, 119-130.

Kosuge, K., Kubo, S., Kikukawa, N., Takemori, M., 2007. Effect of pore structure in mesoporous silicas on VOC dynamic adsorption/desorption performance. Langmuir 23, 3095-3102.

Kümmerer, K., Al-Ahmad, A., Mersch-Sundermann, V., 2000. Biodegradability of some antibiotics, elimination of the genotoxicity and affection of wastewater bacteria in a simple test. Chemosphere 40, 701-710.

Meldrum. B.J., Rochester, C.H., 1990. In situ infrared study of the surface oxidation of activated carbon dispersed in potassium-bromide. J. Chem. Soc. Faraday Trans. 86, 2997-3002. 
Molina-Sabio, M., Muñecas-Vidal, F., Rodriguez-Reinoso, F., 1991. In: Characterization of porous solids II. Ed. Elsevier, Amsterdam.

Monneyron, P., Faur-Brasqet, C., 2002. Competitive adsorption of organic micropollutants in the aqueous phase onto activated carbon cloth. Langmuir 18, 51635168

Nikolaou, A., Meric, S., Fatta, D., 2007. Occurrence patterns of pharmaceuticals in water and wastewater environments. Anal. Bioanal. Chem. 387, 1225-1234.

Oaks, J.L., Gilbert, M., Virani, M.Z., Watson, R.T., Meteyer, C.U., Rideout, B.A., Shivaprasad, H.L., Ahmed, S., Chaudhry, M.J.I., Arshad, M., Mahmood, S., Ali, A., Khan. A.A., 2004. Diclofenac residues as the cause of vulture population decline in Pakistan. Nature 427, 630-633.

O’Reilly, J.M., Mosher, R.A., 1983. Functional groups in carbon black by FTIR spectroscopy. Carbon 21, 47-51.

Paéz, C.A., Contreras, M.S., Léonard, A., Blacher, S., Olivera-Fuentes, C.G., Pirard, J.P., Job, N., 2012. Effect of $\mathrm{CO}_{2}$ activation of carbon xerogels on the adsorption of methylene blue. Adsorption 18, 199-211.

Pekala, R.W., 1989. Organic aerogels from the polycondensation of resorcinol with formaldehyde. J. Mater. Sci. 24, 3221-3227.

Pekala, R.W., Kong, F.M., 1989. Resorcinol-formaldehyde aerogels and their carbonized derivatives. Abstr. Pap. Am. Chem. S. 197, 113-POLY.

Pekala, R.W., Schaefer, D.W., 1993. Structure of organic aerogels. 1. Morphology and scaling. Macromolecules 26, 5487-5493.

Perdigoto, M.L.N., Martins, R.C., Rocha, N., Quina, M.J., Gando-Ferreira, L., Patrício, R., Duraes, L., 2012. Application of hydrophobic silica bases aerogels and xerogels for removal of toxic organic compounds from aqueous solutions. J. Colloid Interf. Sci. 380, 134-140.

Ribeiro, R.S., Fathy, N.A., Attia, A.A., Silva, A.M.T., Faria, J.L., Gomes, H.T., 2012. Activated carbon xerogels for the removal of the anionic azo dyes Orange II and Chromotrope $2 \mathrm{R}$ by adsorption and catalytic wet peroxide oxidation. Chem. Eng. J. 195-196, 112-121.

Seiler, R.L., Zaugg, S.D., Thomas, J.M., Howcroft, D.L., 1999. Caffeine and pharmaceuticals as indicators of waste water contamination in wells. Ground Water 37, 405-410. 
Sellitti, C., Koenig, J.L., Ishida, H., 1990. Surface characterization of graphitized carbon fibers by attenuated total reflection fourier transform infrared spectroscopy. Carbon 28, 221-228.

Siegener, R., Chen, R.F., 2002. Caffeine in Boston Harbor seawater. Mar. Pollut. Bull. 44, 383-387.

Sotelo, J.L., Ovejero, G., Rodríguez, A., Álvarez, S., García, J., 2013a. Adsorption of carbamazepine in fixed bed columns: Experimental and modeling studies. Separ. Sci. Technol. 48, 2626-2637.

Sotelo, J.L., Ovejero, G., Rodríguez, A., Álvarez, S., García, J., 2013b. Analysis and modeling of fixed bed column operations on flumequine removal onto activated carbon: pH influence and desorption studies. Chem. Eng. J. 228, 102-113.

Sotelo, J.L., Rodríguez, A.R., Mateos, M.M., Hernández, S.D., Torrellas, S.A., Rodríguez, J.G., 2012. Adsorption of pharmaceutical compounds and an endocrine disruptor from aqueous solution by carbon materials. J. Environ. Sci. Heal. B 47, 640652.

Sousa, J.P.S., Silva, A.M.T., Pereira, M.F.R., Figueiredo, J.L., 2010. Wet air oxidation of aniline using carbon foams and fibers enriched with nitrogen. Separ. Sci. Technol. 45, 1546-1554.

Suh, D.J., Park, T.J., Ihm, S.K., 1993 Effect of surface oxygen groups of carbon supports on the characteristics of $\mathrm{Pd} / \mathrm{C}$ catalysts. Carbon 31, 427-435.

Ternes, T.A., 1998. Occurrence of drugs in German sewage treatment plants and rivers. Water Res. 32, 3245-3260.

Terzyk, A.P., 2003. Further insights into the role of carbon surface functionalities in the mechanism of phenol adsorption. J. Colloid Interf. Sci. 268, 301-329.

Triebskorn, R., Casper, H., Heyd, A., Eikemper, R., Köhler, H.R., Schwaiger, J., 2004. Toxic effects of the non-steroidal anti-inflammatory drug diclofenac. Part II: citopatological effects in liver, kidney, gills and intestine of rainbow trout (Oncorhynchusmykiss). Aquat. Toxicol. 68, 151-166.

Urase, T., Sato, K., 2007. The effect of deterioration of nanofiltration membrane on retention of pharmaceuticals. Desalination 202, 385-391.

Vinke, P., Van der Eijk, M., Verbree, M., Voskamp, A.F., Van Bekkum, H., 1994. Modification of the surfaces of a gas activated carbon and a chemically activated carbon with nitric acid, hypochlorite, and ammonia. Carbon 32, 675-686. 


\section{Figure captions:}

Fig 1. $\mathrm{N}_{2}$ adsorption-desorption isotherms of the tested carbon xerogels.

Fig 2. Pore size distribution of the tested carbon xerogels.

Fig 3. SEM micrographs of (a) CX; (b) CXN; (c) CXNUT; (d) CXS carbon xerogels.

Fig 4. FTIR spectra of the tested carbon xerogels.

Fig 5. Adsorption kinetic curves of (a) caffeine; (b) diclofenac onto carbon xerogels.

Fig 6. Adsorption isotherms of (a) caffeine; (b) diclofenac onto carbon xerogels.

Fig 7. Adsorption capacities of (a) caffeine; (b) diclofenac onto carbon xerogels.

Fig 8. Initial adsorption rates versus isoelectric point of caffeine and diclofenac onto carbon xerogels. 
Table 1. Textural and chemical properties of the tested carbon xerogels.

\begin{tabular}{|c|c|c|c|c|c|c|c|c|c|c|}
\hline \multirow[b]{2}{*}{ Carbon } & \multicolumn{4}{|c|}{$\mathrm{N}_{2}$ adsorption at $-196^{\circ} \mathrm{C}$} & \multicolumn{5}{|c|}{ Elemental microanalysis } & \multirow[t]{2}{*}{ pH $\mathbf{H}_{\text {IEP }}$} \\
\hline & $\begin{array}{c}S_{\text {BET }} \\
\left(m^{2} \cdot g^{-1}\right)\end{array}$ & $\begin{array}{c}\mathbf{V}_{\mathbf{P}} \\
\left(\mathrm{cm}^{3} \cdot \mathrm{g}^{-1}\right)\end{array}$ & $\begin{array}{c}V_{0} \\
\left(\mathrm{~cm}^{3} \cdot \mathrm{g}^{-1}\right)\end{array}$ & $\begin{array}{c}V_{m} \\
\left(\mathrm{~cm}^{3} \cdot \mathrm{g}^{-1}\right)\end{array}$ & $\begin{array}{c}\mathbf{N} \\
(\%)\end{array}$ & $\begin{array}{c}C \\
(\%)\end{array}$ & $\begin{array}{c}H \\
(\%)\end{array}$ & $\begin{array}{c}\mathbf{O} \\
(\%)\end{array}$ & $\begin{array}{c}S \\
(\%)\end{array}$ & \\
\hline $\mathbf{C X}$ & 367 & 0.75 & 0.26 & 0.48 & 0.08 & 91.26 & 1.00 & 7.65 & 0.01 & 4.5 \\
\hline CXN & 347 & 0.76 & 0.30 & 0.46 & 0.91 & 68.61 & 2.27 & 28.20 & 0.01 & 1.1 \\
\hline CXNUT & 435 & 0.72 & 0.28 & 0.45 & 2.81 & 80.99 & 1.85 & 14.32 & 0.03 & 6.9 \\
\hline CXS & 288 & 0.70 & 0.20 & 0.50 & 0.12 & 79.13 & 1.74 & 17.52 & 1.49 & 2.8 \\
\hline
\end{tabular}

$\mathrm{S}_{\mathrm{BET}}$ : Surface area, $\mathrm{V}_{\mathrm{P}}$ : Total pore volume, $\mathrm{V}_{0}$ : Micropore volume, $\mathrm{V}_{\mathrm{m}}$ : Mesopore volume, $\mathrm{pH}_{\mathrm{IEP}}$ : Isoelectric point. 
Table 2. Kinetic data predicted by pseudo-first order and pseudo-second order models for adsorption of caffeine and diclofenac by carbon xerogels.

\begin{tabular}{|c|c|c|c|c|c|c|c|c|}
\hline Caffeine & \multicolumn{4}{|c|}{ Pseudo-first order model } & \multicolumn{4}{|c|}{ Pseudo-second order model } \\
\hline Carbon & $\begin{array}{c}q_{e} \exp \\
\left(\mathrm{mg} \mathrm{g}^{-1}\right)\end{array}$ & $\begin{array}{c}q_{\mathrm{e}} \text { cal } \\
\left(\mathrm{mg} \mathrm{g}^{-1}\right)\end{array}$ & $\begin{array}{c}\mathbf{k}_{1} \\
\left(\mathbf{h}^{-1}\right)\end{array}$ & $\mathbf{R}^{2}$ & $\begin{array}{c}\text { qe cal } \\
\left(\mathrm{mg} \mathrm{g}^{-1}\right)\end{array}$ & $\begin{array}{c}k_{2} \\
\left(\mathrm{~g} \mathrm{mg}^{-1} h^{-1}\right)\end{array}$ & $\begin{array}{l}\mathbf{t}_{1 / 2} \\
\text { (h) }\end{array}$ & $\mathbf{R}^{2}$ \\
\hline $\mathbf{C X}$ & 38.7 & 10.9 & 0.06 & 0.6880 & 39.1 & 0.04 & 0.6 & 0.9996 \\
\hline $\mathbf{C X N}$ & 37.4 & 21.7 & 0.07 & 0.9264 & 40.0 & 0.01 & 3.3 & 0.9978 \\
\hline CXNUT & 36.8 & 3.9 & 0.04 & 0.2439 & 36.9 & 0.60 & 0.1 & 1.0000 \\
\hline CXS & 28.5 & 16.4 & 0.06 & 0.9131 & 29.1 & 0.02 & 1.6 & 0.9973 \\
\hline Diclofenac & \multicolumn{4}{|c|}{ Pseudo-first order model } & \multicolumn{4}{|c|}{ Pseudo-second order model } \\
\hline Carbon & $\begin{array}{c}q_{e} \exp \\
\left(\mathrm{mg} \mathrm{g}^{-1}\right)\end{array}$ & $\begin{array}{c}\mathrm{q}_{\mathrm{e}} \text { cal } \\
\left(\mathrm{mg} \mathrm{g}^{-1}\right)\end{array}$ & $\begin{array}{c}\mathbf{k}_{1} \\
\left(\mathbf{h}^{-1}\right)\end{array}$ & $\mathbf{R}^{2}$ & $\begin{array}{c}\mathrm{q}_{\mathrm{e}} \text { cal } \\
\left(\mathrm{mg} \mathrm{g}^{-1}\right)\end{array}$ & $\begin{array}{c}k_{2} \\
\left(\mathrm{~g} \mathrm{mg}^{-1} h^{-1}\right)\end{array}$ & $\begin{array}{l}\mathbf{t}_{1 / 2} \\
\text { (h) }\end{array}$ & $\mathbf{R}^{2}$ \\
\hline $\mathbf{C X}$ & 32.4 & 18.0 & 0.07 & 0.8818 & 33.6 & 0.02 & 1.9 & 0.9967 \\
\hline $\mathbf{C X N}$ & 33.8 & 16.4 & 0.07 & 0.8927 & 35.6 & 0.01 & 2.5 & 0.9990 \\
\hline CXNUT & 38.7 & 15.8 & 0.08 & 0.6392 & 39.7 & 0.02 & 1.3 & 0.9983 \\
\hline CXS & 40.2 & 8.4 & 0.05 & 0.5070 & 40.5 & 0.07 & 0.3 & 0.9999 \\
\hline
\end{tabular}


Table 3. Adsorption model parameters for caffeine and diclofenac removal by carbon xerogels.

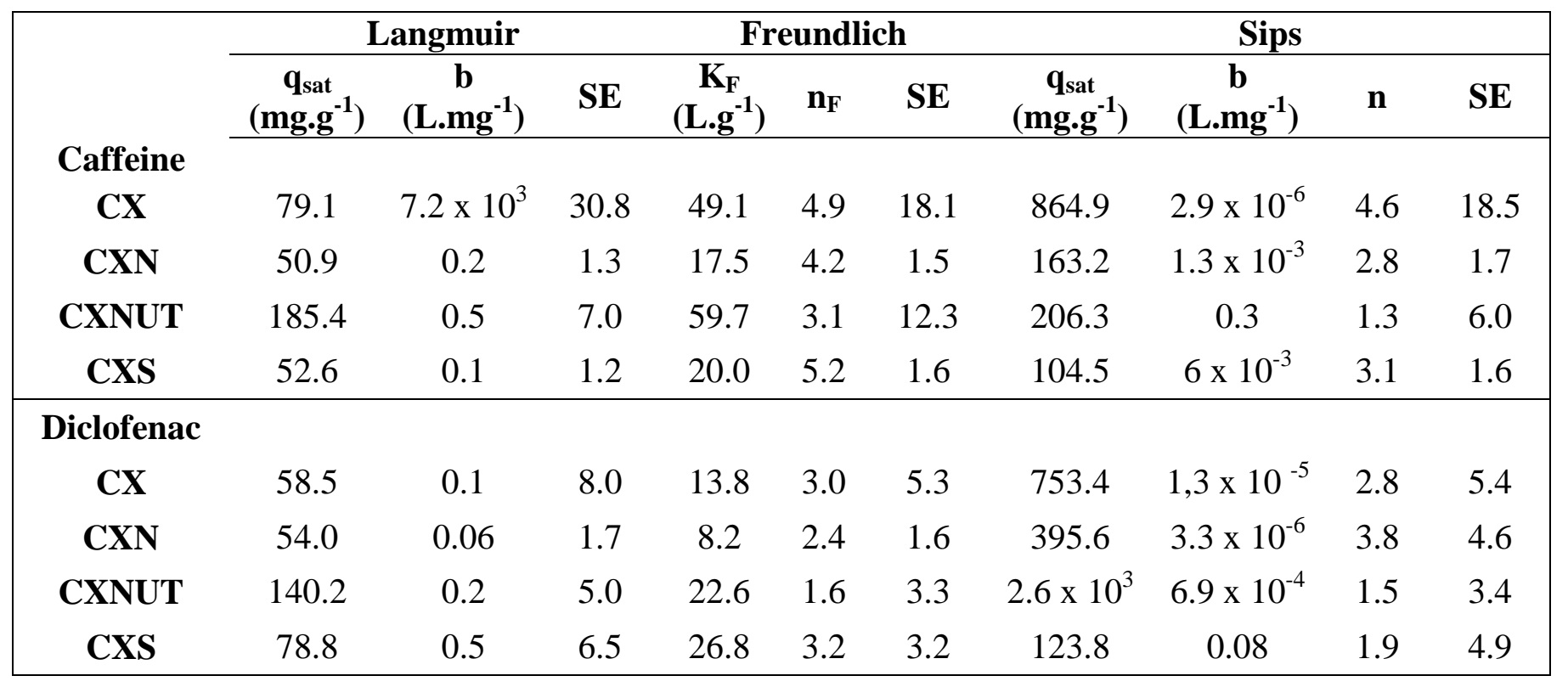


Table 4. References about contaminants adsorption on carbon xerogels.

\begin{tabular}{|cccc|}
\hline Adsorbent & Contaminant & $\begin{array}{c}\text { qexp } \\
\left(\mathbf{m g . g}^{-\mathbf{1}}\right)\end{array}$ & Reference \\
\hline $\begin{array}{c}\text { Carbon xerogel } \\
\text { treated with an urea } \\
\text { solution }\end{array}$ & Caffeine & 182.5 & Our study \\
$\begin{array}{c}\text { Carbon xerogels } \\
\text { treated with urea and }\end{array}$ & Diclofenac & 80.0 & Our study \\
$\mathrm{H}_{2} \mathrm{SO}_{4}$ solutions & & & \\
Carbon xerogel & Methylene Blue & 650.0 & Paéz et al. 2012 \\
activated during 16 $\mathrm{h}$ & Benzene & 68.8 & \\
& Toluene & 90.0 & Perdigoto et al. 2012 \\
Silica-based xerogels & Phenol & 5.0 & \\
& Cu (II) & 130.0 & Girgis et al. 2012 \\
Carbon xerogel & Reactive dye & 220.0 & Figueiredo et al. 2011 \\
Carbon xerogel & Methylene Blue & 225.0 & Girgis et al. 2011 \\
Carbon xerogel & Rhodamine B & 160.0 & . \\
\hline
\end{tabular}






Figure 1. $\mathrm{N}_{2}$ adsorption-desorption isotherms of the tested carbon xerogels. 


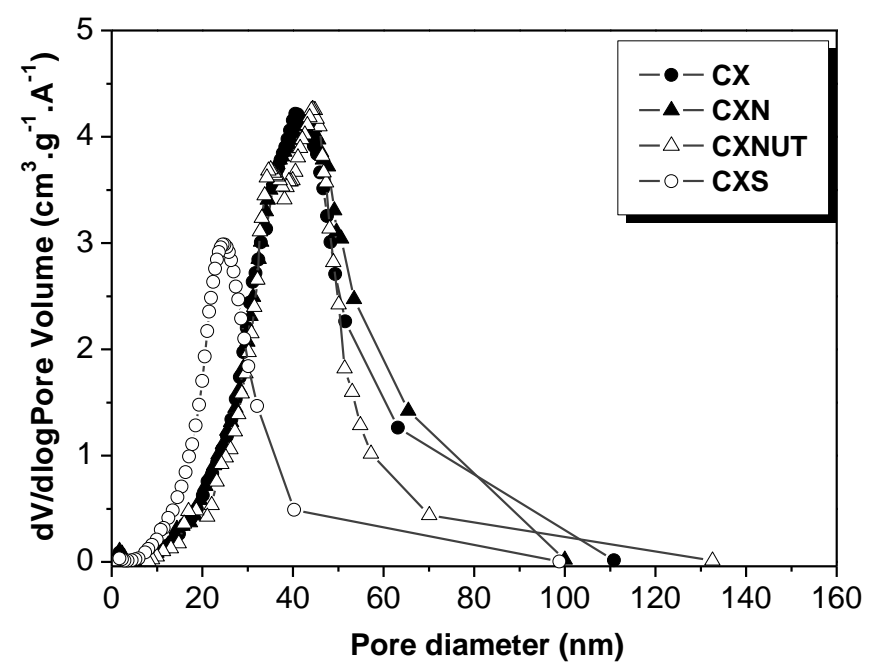

Figure 2. Pore size distribution of the tested carbon xerogels. 

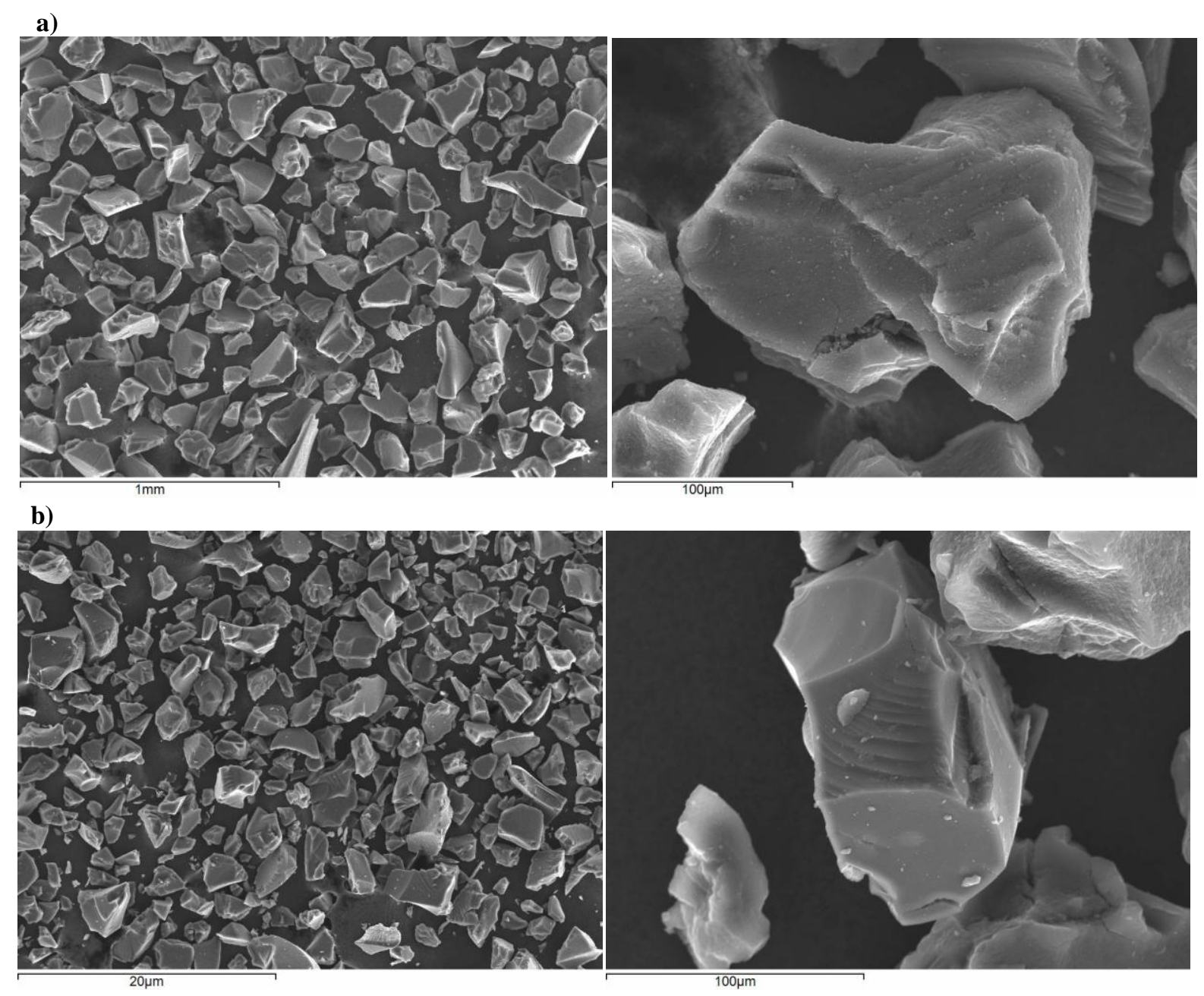
c)

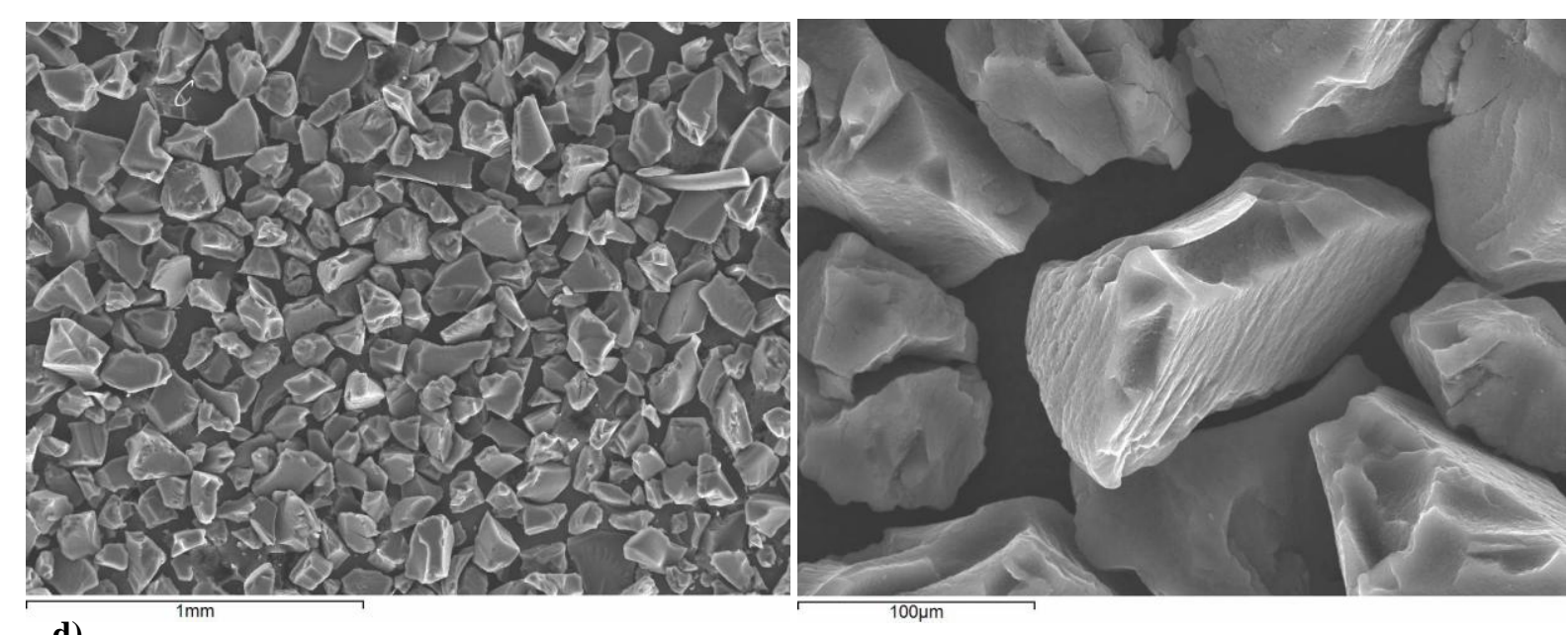

d)



Figure 3. SEM micrographs of (a) CX; (b) CXN; (c) CXNUT; (d) CXS carbon xerogels. 


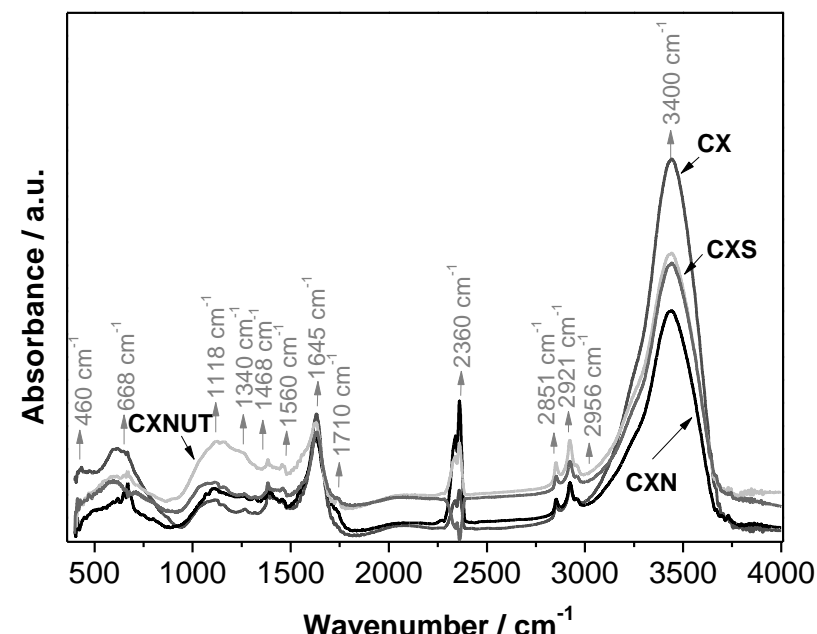

Figure 4. FTIR spectra of the tested carbon xerogels. 
a)

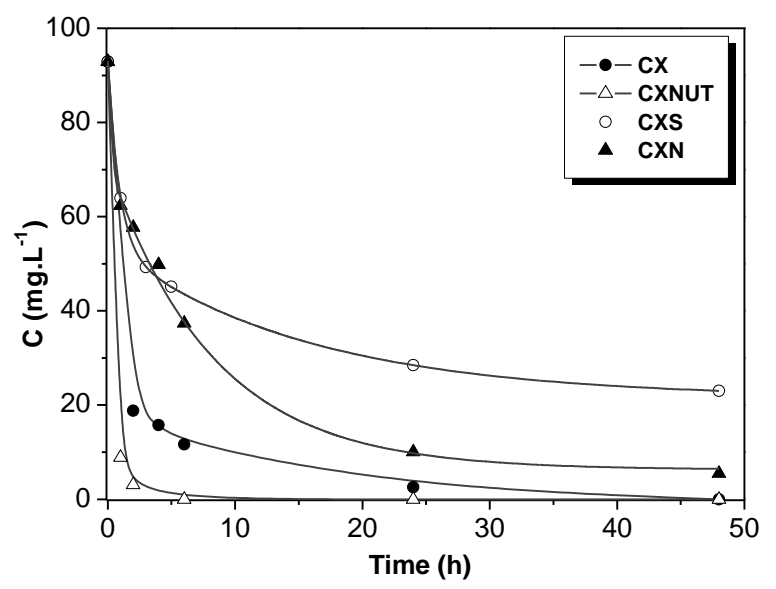

b)

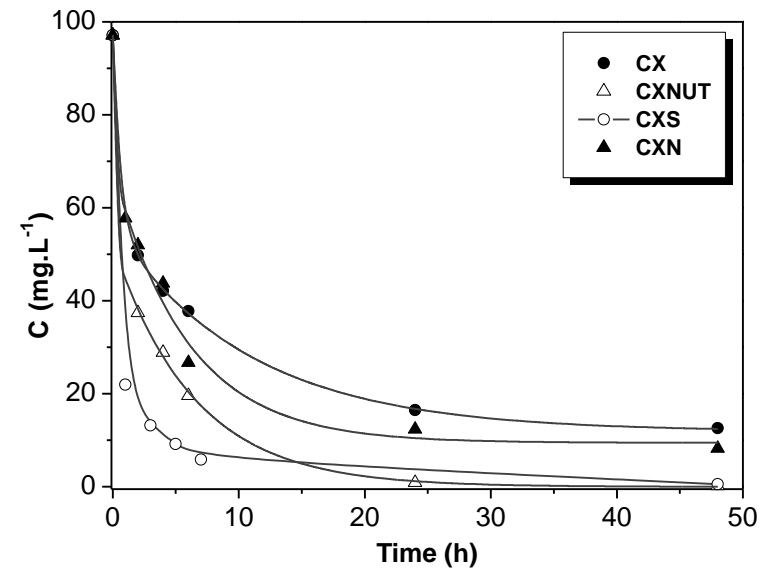

Figure 5. Adsorption kinetic curves of (a) caffeine; (b) diclofenac onto carbon xerogels. 

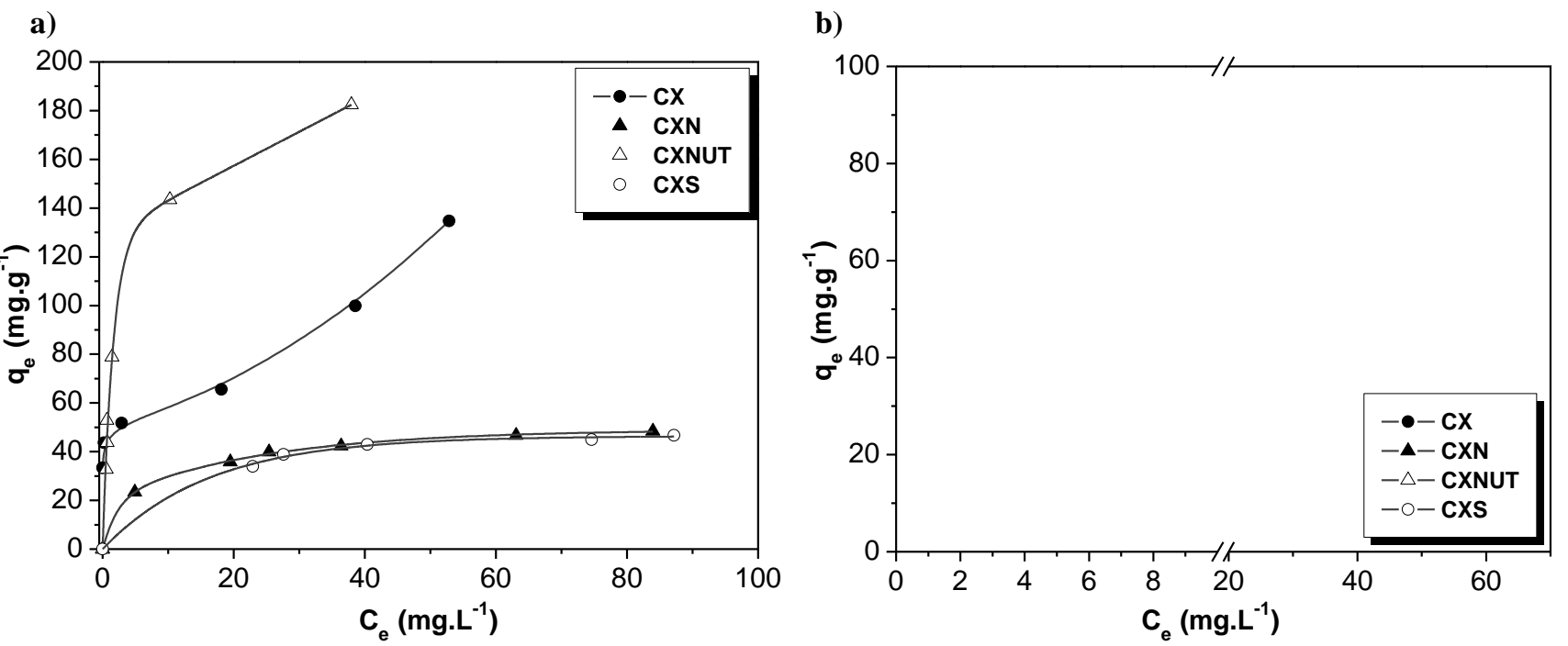

Figure 6. Adsorption isotherms of (a) caffeine; (b) diclofenac onto carbon xerogels. 


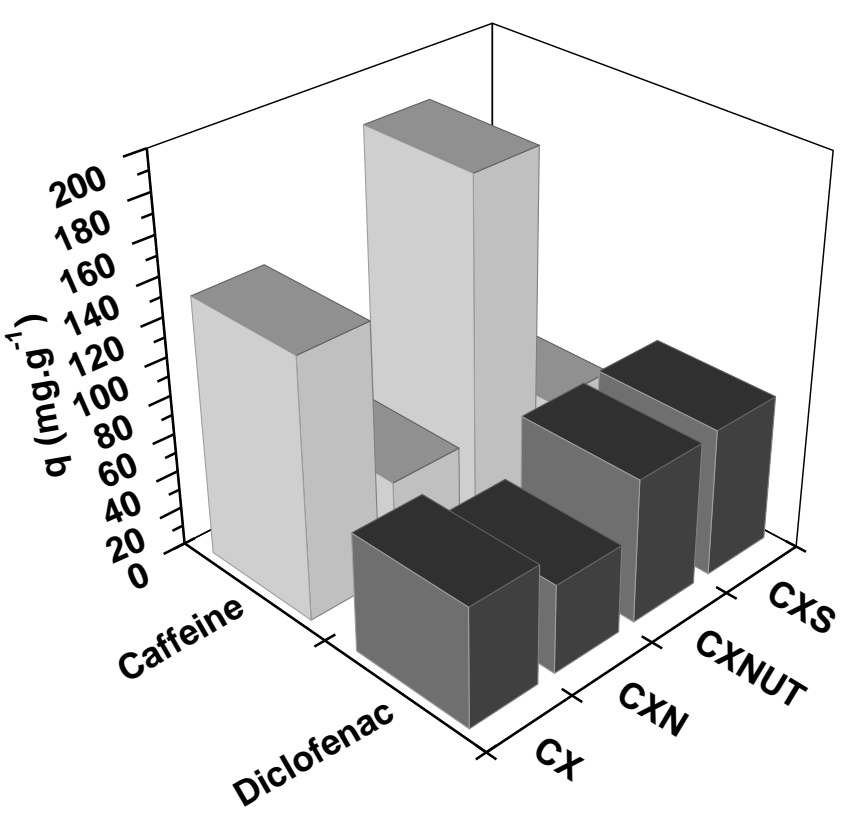

Figure 7. Adsorption capacities of (a) caffeine; (b) diclofenac onto carbon xerogels. 


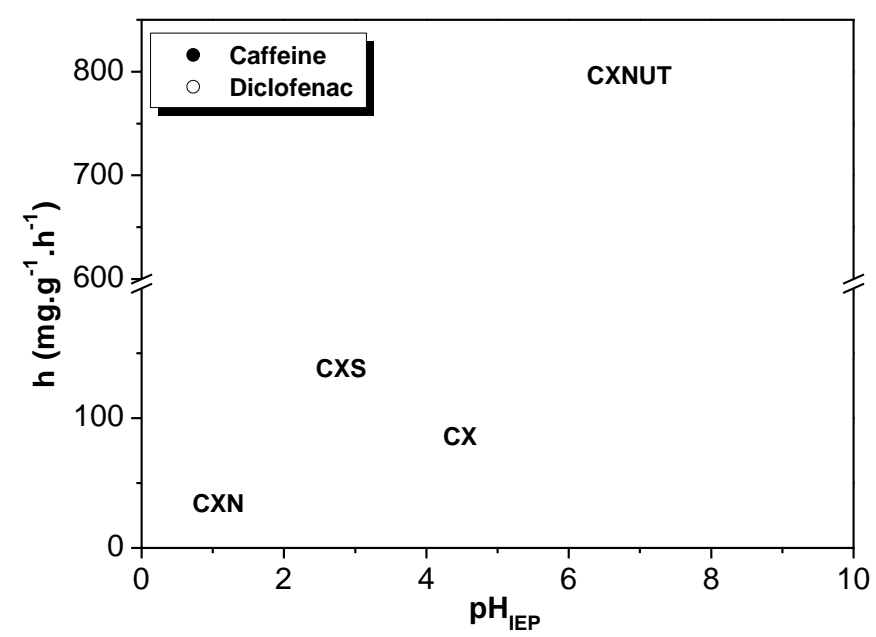

Figure 8. Initial adsorption rates versus isoelectric point of caffeine and diclofenac onto carbon xerogels. 